\title{
Wall Composition of Monokaryons and Dikaryons of Coprinus cinereus
}

\author{
By ROGER MARCHANT \\ School of Biological and Environmental Studies, New University of Ulster, \\ Coleraine, County Londonderry, Northern Ireland
}

(Received 22 November 1977)

\section{INTRODUCTION}

The only basidiomycete whose wall structure and composition has been studied in detail is Schizophyllum commune (Hunsley \& Burnett, 1970; Wessels et al., 1972; de Vries \& Wessels, 1973; van der Valk, Marchant \& Wessels, 1977). In this species, the monokaryon wall contains only a small proportion of chitin (5 to $10 \%)$, together with an alkali-soluble $(1 \rightarrow 3)$ - $\alpha$-glucan (S-glucan) and an alkali-resistant $(1 \rightarrow 3)-\beta,(1 \rightarrow 6)$ - $\beta$-glucan (R-glucan). Michalenko, Hohl \& Rast (1976) have shown that the hyphal wall of the dikaryon of Agaricus bisporus contains $43 \%$ chitin, $14 \%$ alkali-soluble glucan and $27 \%(1 \rightarrow 3)$ - $\beta$-glucan together with a layer of $\beta$-glucan mucilage on the outer surface. More recently, Schaefer (1977) has published structural information on the alkali-soluble fraction of the wall of Coprinus cinereus, but under the name C. lagopus.

Fragmentary information is available for a number of other basidiomycete species: Agaricus campestris (Kreger, 1954), 14 members of the Polyporaceae and 6 other basidiomycete species (O'Brien \& Ralph, 1966), and other members of the Polyporaceae. These analyses were largely concerned with one component, or a small number of components, of the wall system and no attempt was made to draw comparisons between different developmental stages. Wessels (1965) has noted changes in the hyphal walls of fruiting cultures of $S$. commune, but these relate to the production of thick-walled hyphae at the base of fruit bodies.

There has been no detailed comparison of the wall composition of the primary (monokaryon), secondary (dikaryon) and tertiary (fruit body) mycelium in any basidiomycete. The object of the present investigation was to examine the composition of the wall of C. cinereus at different developmental phases to determine what differences, if any, occur.

\section{METHODS}

Organism. The strains of Coprinus cinereus (Schaeff. ex Fr.) S. F. Gray used in this study were monokaryon strains $\mathrm{H} 9$ and TC4 and dikaryon strain $\mathrm{H} 9 \times \mathrm{TC} 4$ kindly provided by Dr Lorna A. Casselton, Queen Mary College, London. Stock cultures were maintained on slopes of $2 \%(\mathrm{w} / \mathrm{v})$ malt agar. Hyphal material was obtained from stationary, illuminated, liquid cultures incubated at $30{ }^{\circ} \mathrm{C}$ for 8 to $9 \mathrm{~d}$, when the organism was at the end of its exponential phase of growth. One litre Erlenmeyer flasks containing $100 \mathrm{ml}$ minimal liquid medium were inoculated with $2 \mathrm{ml}$ of macerated plate culture. The minimal medium contained (per litre): glucose, $20.0 \mathrm{~g}$; L-asparagine, $1.5 \mathrm{~g} ; \mathrm{KH}_{2} \mathrm{PO}_{4}, 1.0 \mathrm{~g} ; \mathrm{MgSO}_{4} .7 \mathrm{H}_{2} \mathrm{O}, 0.5 \mathrm{~g} ; \mathrm{FeCl}_{3} .6 \mathrm{H}_{2} \mathrm{O}, 5.0 \mathrm{mg}$; $\mathrm{H}_{3} \mathrm{BO}_{3}, 0.06 \mathrm{mg} ;\left(\mathrm{NH}_{4}\right)_{6} \mathrm{Mo}_{7} \mathrm{O}_{24} .4 \mathrm{H}_{2} \mathrm{O}, 0.04 \mathrm{mg} ; \mathrm{CuSO}_{4} .5 \mathrm{H}_{2} \mathrm{O}, 0.2 \mathrm{mg} ; \mathrm{ZnSO}_{4} .7 \mathrm{H}_{2} \mathrm{O}, 2.0 \mathrm{mg} ; \mathrm{MnSO}_{4}$. $4 \mathrm{H}_{2} \mathrm{O}, 0.1 \mathrm{mg} ; \mathrm{CoCl}_{2} \cdot 6 \mathrm{H}_{2} \mathrm{O}, 0.4 \mathrm{mg} ; \mathrm{Ca}\left(\mathrm{NO}_{3}\right)_{2} .4 \mathrm{H}_{2} \mathrm{O}, 1.2 \mathrm{mg}$; thiamin hydrochloride, $120 \mu \mathrm{g}$. Fruit bodies were obtained by inoculating boxes of commercial mushroom compost with the dikaryon strain as described previously (Blayney \& Marchant, 1977). Fruit bodies were harvested at stages III or IV (Borriss, 1934) and the stipes removed. Isolation of wall material from the stipes was carried out in the same way as for the hyphal material. Attempts to obtain fruit bodies on defined medium, as suggested by Casselton \& Casselton (1966), were unsuccessful. 
Isolation of wall material. Material was first disrupted in an X-Press (Biotec, Stockholm, Sweden), then washed three times in $0.05 \mathrm{M}$-Sorensen's buffer (Tris/ $\mathrm{HCl}) \mathrm{pH} 7.0$. The wall material was collected each time by centrifugation at $4000 \mathrm{~g}$. It was further washed three times in $0.05 \mathrm{M}$-Mcllvaine's buffer $\left(\mathrm{KH}_{2} \mathrm{PO}_{4} /\right.$ $\mathrm{NaOH}) \mathrm{pH} 5 \cdot 5$, once in water, once in absolute ethanol/petroleum ether (b.p. 60 to $\left.80^{\circ} \mathrm{C}\right)(1: 1$, v/v), once in petroleum ether (b.p. 60 to $80^{\circ} \mathrm{C}$ ) and finally in water before being freeze-dried. The total breakage of hyphae and absence of cytoplasmic contamination was confirmed by light and electron microscopy.

Alkali extraction of wall material. Weighed amounts of dry wall material (300 to $400 \mathrm{mg}$ ) were incubated for $16 \mathrm{~h}$ in $30 \mathrm{ml} 5 \%(\mathrm{w} / \mathrm{v}) \mathrm{KOH}$ at $25^{\circ} \mathrm{C}$. Residual material was thoroughly washed by centrifugation with water and $20 \%(\mathrm{v} / \mathrm{v})$ acetic acid, and the washings were combined. The alkali-resistant material (R-fraction) was dried to constant weight at $37^{\circ} \mathrm{C}$. The supernatant was adjusted to pH 5.0 with acetic acid and any precipitate (S-fraction) was collected, dried and weighed. The remaining supernatant was made up to a known volume and retained for chemical analyses.

Chemical determinations. Total hexose content of whole walls and fractions was determined by the anthrone method (Fairbairn, 1953), using glucose as standard and correcting the values for polymerization. Total pentose content was estimated using the cysteine reaction (Dische, 1955), with xylose as standard and correcting the values for polymerization. Chitin was determined by the method of Roseman \& Daffner (1956), after hydrolysing the material for $6 \mathrm{~h}$ at $100^{\circ} \mathrm{C}$ in $3 \mathrm{M}-\mathrm{HCl}$. Crab chitin (Sigma) was hydrolysed under identical conditions and used as a standard. Protein was estimated by the method of Lowry et al. (1951), using bovine serum albumin as standard.

Chromatography. The sugar compositions of whole walls and wall fractions were determined by hydrolysing $10 \mathrm{mg}$ material for $6 \mathrm{~h}$ at $100^{\circ} \mathrm{C}$ in $3 \mathrm{ml} 1 \mathrm{M}-\mathrm{HCl}$. After removal of the excess acid under vacuum, the sugars were taken up in water and separated by either thin-layer chromatography or paper chromatography. Thin-layer chromatography was done on $150 \mu \mathrm{m}$ thick layers of Kieselguhr G buffered with $0.02 \mathrm{M}$-sodium acetate, activated at $100{ }^{\circ} \mathrm{C}$ for $30 \mathrm{~min}$. The plates were run in ethyl acetate/2-propanol/water $(65: 23 \cdot 5: 11 \cdot 5$, by vol.), sprayed with anisaldehyde/sulphuric acid reagent $[9 \mathrm{ml} 95 \%(\mathrm{v} / \mathrm{v})$ ethanol, $0.5 \mathrm{ml}$ concentrated $\mathrm{H}_{2} \mathrm{SO}_{4}$ and $0.5 \mathrm{ml}$ anisaldehyde] and developed at $100^{\circ} \mathrm{C}$. Paper chromatography was done on Whatman no. 1 paper using ethyl acetate/acetic acid/water (700:150:150, by vol.) as solvent for $16 \mathrm{~h}$. After drying, the chromatograms were sprayed with aniline/diphenylamine reagent $[1 \%(\mathrm{v} / \mathrm{v})$ aniline in a solution of $1 \frac{1}{1}(\mathrm{w} / \mathrm{v})$ diphenylamine in acetone $/ 65 \%(\mathrm{w} / \mathrm{v}) \mathrm{H}_{3} \mathrm{PO}_{4}(90: 10$, by vol. $\left.)\right]$ and heated at $100{ }^{\circ} \mathrm{C}$ for $5 \mathrm{~min}$.

\section{RESULTS}

\section{Wall composition}

The alkali-resistant fraction (R-fraction) of the four wall samples represented approximately $70 \%$ of the whole wall: monokaryon $\mathrm{H} 9,68.6 \%$ (w/w); monokaryon TC4, $65.5 \%$ $(\mathrm{w} / \mathrm{w})$; dikaryon vegetative phase, $72.5 \%(\mathrm{w} / \mathrm{w})$; and stipes, $64.7 \%(\mathrm{w} / \mathrm{w})$. Only in the monokaryons was any of the material removed by the alkali treatment subsequently reprecipitated by $\mathrm{pH}$ adjustment (S-fraction). In monokaryon $\mathrm{H} 9$ this represented $10 \cdot 1 \%(\mathrm{w} / \mathrm{w})$ of the wall while in monokaryon TC4 it was $5 \cdot 3 \%(\mathrm{w} / \mathrm{w})$ of the wall.

The composition of the isolated walls and wall fractions from the four samples is given in Table 1. The determinations were carried out at least four times on each of two separately grown batches of wall material to give the mean values shown. The most striking feature of the whole wall compositions was the variation in chitin content, which was balanced by changes in the hexose composition. The monokaryon walls contained 33.4 and $26.8 \%(w / w)$ chitin, together with a small percentage of pentose in one case. In the vegetative dikaryon, the chitin content fell to $10.1 \%(\mathrm{w} / \mathrm{w})$ with no pentose present and the hexose content rose accordingly. In the stipes of the same dikaryon strain, the chitin content was again high $(43.3 \%, \mathrm{w} / \mathrm{w})$. The analyses of the alkali-resistant $\mathrm{R}$-fraction of these walls indicated that hexose and protein were the components largely removed from whole walls by alkali treatment, although in the monokaryon strains some glucosamine was also removed in the S-fraction. Although the S-fraction represented only a small proportion of the total wall in the monokaryons, it was completely absent from the other wall samples. The alkali-soluble residue of each of the wall samples was mainly composed of hexose and protein, with a small amount of pentose in one monokaryon. 
Table 1. Composition $(\%, w / w)$ of isolated walls and wall fractions from Coprinus cinereus

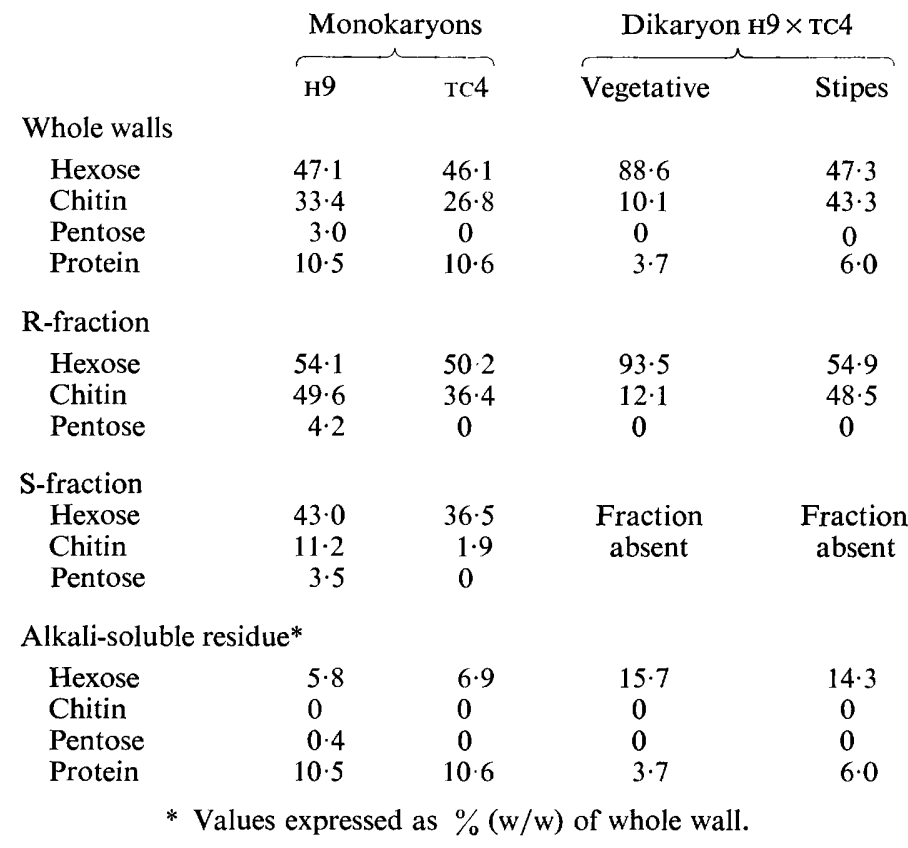

Sugar components of the walls

Chromatography of hydrolysates of the whole walls and wall fractions of each of the samples indicated major differences in their compositions. The whole walls of the monokaryon $\mathrm{H} 9$ contained glucose, mannose, ribose, xylose and rhamnose. Glucose was present in greatest quantity, with a smaller amount of mannose, less xylose and ribose, and a trace of rhamnose. The R-fraction of this monokaryon contained glucose in large quantity and traces of xylose and rhamnose. The S-fraction contained each of the five sugars detected, with glucose and mannose present in equivalent amounts and low levels of the other three sugars. Chromatography of hydrolysates of the monokaryon TC4 revealed only glucose.

The two dikaryon samples both showed only glucose in the hydrolysates of whole walls and R-fractions. Chromatography of the alkali-soluble residues, without acid hydrolysis, indicated that single sugar residues or small oligosaccharides were absent in each case.

\section{DISCUSSION}

Although changes in wall composition associated with dimorphic forms of fungi have been investigated extensively, no effort has so far been made to determine if there are any similar changes associated with the developmental phases of basidiomycete fungi as they pass from the monokaryotic to dikaryotic phase before finally producing large fruiting structures. The work of Wessels and his group seems to indicate that there are no dramatic changes in wall composition associated with fruiting in $S$. commune, except in the production of thick-walled hyphae. Only one other basidiomycete has received extensive examination of the type to which $S$. commune has been subjected: this is $C$. cinereus (often misnamed C. lagopus). Frey (1950) showed the presence of chitin in the walls of Coprinus by X-ray diffraction methods, and Schaefer (1977) has isolated an alkali-soluble $\beta$-glucan from the wall, but apart from this there is no information on the wall structure.

The present study has shown that large differences occur in the composition of the walls at different stages. The values of 33.4 and $26.8 \%$ chitin in the walls of the monokaryons 
compare favourably with the values for other basidiomycetes quoted by O'Brien \& Ralph (1966). It is difficult, however, to be certain of the values given by O'Brien \& Ralph since they did not give details of the strains used, and their value for the chitin content of $S$. commune is widely different from that of Wessels (1965). Gooday (1977) has also shown that chitin synthesis occurs rapidly in developing stipes of $C$. cinereus which may account for the high chitin levels observed. It is unfortunate that the dikaryon could not be induced to fruit on defined medium; however, the value for chitin content of the stipes is still valuable for comparison. The anomalous chitin content value is in the secondary mycelial phase where it falls to $10 \cdot 1 \%$. In most basidiomycetes the extension growth of the dikaryon is more rapid than that of the monokaryon (see, for example, Kaufert, 1936). This phenomenon is most easily seen when carrying out a mating of two monokaryons on a plate. The synthesis of the glucan and chitin components of the wall may not therefore be rigidly integrated, and under conditions of rapid vegetative hyphal extension growth, glucan synthesis may be relatively more rapid than chitin synthesis. When fruit bodies are initiated, extension growth in the initial becomes less rapid and the hyphae become extensively branched in the region which will become the stipe (van der Valk \& Marchant, 1978). This slowing of tip extension growth may contribute to the increase in the chitin content of the stipes.

There are other differences between the monokaryon and dikaryon strains, despite the fact that the monokaryon strains are the parents of thedikaryon. The four samples all appear to have the alkali-soluble $(1 \rightarrow 3)$-linked $\beta$-glucan with $(1 \rightarrow 6)$-linked branch points on $14 \%$ of the residues, as described by Schaefer (1977), but the monokaryons have a mixed fraction forming about $10 \%$ of the wall which can be reprecipitated from the alkali-soluble fraction in the same way that the S-fraction of $S$. commune can be precipitated. The S-fraction of $S$. commune is an almost pure $\alpha$-linked glucan (Wessels et al., 1972) and thus differs markedly from the S-fraction of at least strain $\mathrm{H} 9$ of $C$. cinereus. The dikaryon samples totally lacked this S-fraction. The variations in protein content of the wall samples are difficult to relate to development or structure, but the values are somewhat less than those observed by Michalenko et al. (1976) for Agaricus bisporus.

These results emphasize the magnitude of the changes which accompany fruiting in basidiomycetes and also the care which must be exercised in defining the stage of the organism with which one is working.

I wish to thank Mrs S. McMullan for her invaluable technical assistance.

\section{REFERENCES}

Blayney, G. P. \& Marchant, R. (1977). Glycogen and protein inclusions in elongating stipes of Coprinus cinereus. Journal of General Microbiology 98, 467-476.

BorRISS, H. (1934). Beträge zur Wachstums- und Entwicklungs-physiologie der Fruchtkörper von Coprinus lagopus. Planta 22, 28-69.

Casselton, L. A. \& Casselton, P. J. (1966). Control of fruiting of Coprinus lagopus on certain synthetic media. Transactions of the British Mycological Society 49, 579-581.

DisChe, Z. (1955). New color reactions for determinations of sugars in polysaccharides. In Methods of Biochemical Analysis, vol. II. Edited by D. Glick. New York: Interscience.

FairbairN, N. J. (1953). A modified anthrone reagent. Chemistry and Industry 72, 86.

Frey, R. (1950). Chitin und Zellulose in Pilzzellwänden. Bericht der Schweizerischen botanischen Gesellschaft 60, 199-230.

Gooday, G. W. (1977). Biosynthesis of the fungal wall - mechanisms and implications. Journal of General Microbiology 99, 1-11.

Hunsley, D. \& Burnett, J. H. (1970). The ultrastructural architecture of the walls of some hyphal fungi. Journal of General Microbiology 62, 203218.

Kaufert, F. H. (1936). The biology of Pleurotus corticatus Fries. University of Minnesota Agricultural Experiment Station Bulletin 114, 1-35.

KREGER, D. R. (1954). Observations on cell walls of yeasts and some other fungi by X-ray diffraction and solubility tests. Biochimica et biophysica acta 13, 1-9.

LoWry, O. H., Rosebrough, N. J., Farr, A. L. \& RANDALL, R. J. (1951). Protein measurement with the Folin phenol reagent. Journal of Biological Chemistry 193, 265-275.

Michalenko, G. O., Hohl, H. R. \& Rast, D. (1976). Chemistry and architecture of the mycelial 
wall of Agaricus bisporus. Journal of General Microbiology 92, 251-262.

O'BRIEN, R. W. \& RALPH, B. J. (1966). The cell wall composition and taxonomy of some basidiomycetes and ascomycetes. Annals of Botany 30, 831-843.

Roseman S. \& Daffner I. (1956). Colorimetric method for determination of glucosamine and galactosamine. Analytical Chemistry 28, 17431746.

SCHAEFER, H. P. (1977). An alkali-soluble polysaccharide from the cell walls of Coprinus lagopus. Archives of Microbiology 113, 79-82.

VAN DER VAlK, P. \& Marchant, R. (1978). Hyphal ultrastructure in fruit body primordia of the basidiomycetes Schizophyllum commune and Coprinus cinereus. Protoplasma (in the Press).

VAN der Valk, P., Marchant, R. \& Wessels, J. G. H. (1977). Ultrastructural localization of polysaccharides in the wall and septum of the basidiomycete Schizophyllum commune. Experimental Mycology 1, 69-82.

de VRIES, O. M. H. \& Wessels, J. G. H. (1973). Release of protoplasts from Schizophyllum commune by combined action of purified $\alpha-1,3-$ glucanase and chitinase derived from Trichoderma viride. Journal of General Microbiology 76, 319330.

Wessels, J. G. H. (1965). Morphogenesis and biochemical processes in Schizophyllum commune. Wentia 13, 1-113.

Wessels, J. G. H., Kreger, D. R., Marchant, R., Regensburg, B. A. \& DE VRIES, O. M. H. (1972). Chemical and morphological characterization of the hyphal wall surface of the basidiomycete Schizophyllum commune. Biochimica et biophysica acta 273, 346-358. 